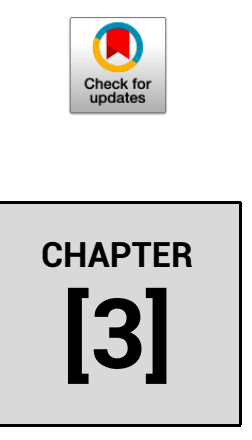

In: Environmental Degradation: Causes and Remediation Strategies

DOI: 10.26832/aesa-2020-edcrs-03

\title{
Role of pesticide application in environmental degradation and its remediation strategies
}

\author{
Sudhanshu Bala Nayak ${ }^{1 *}$, Alok Kumar Sahoo ${ }^{2}$, \\ Elango K. ${ }^{3}$ and K. Sankara Rao ${ }^{1}$
}

\footnotetext{
${ }^{1}$ Department of Entomology, CCS Haryana Agricultural University (CCSHAU), Hisar-125004, India ${ }^{2}$ Subject Matter Specialist (Agricultural Extension), KVK, Bargarh, OUAT, Gambharipali-768102, India

${ }^{3}$ Department of Entomology, Tamil Nadu Agricultural University, Coimbatore-641003, India
}

The modern agriculture is heavily dependent on agrochemicals like fertilizer, pesticides, micronutrients and plant growth regulators for food and livelihood security in the world. In India, the consumption pattern of pesticides includes insecticides (61.11\%), herbicides (22.22\%) and fungicides (11.11\%). Cotton and vegetables are high pesticides consuming agro-products followed by staple food grains (Rice, Wheat, Corn, Millets). The inappropriate toxic chemicals exposure is not only poisoning \& killing of farm families but also dispersing pesticide residues in the environment causing mass killings of nonhuman biotas, such as bees, birds, amphibians, fish, and small mammals. The organophosphate (diazinon, malathion, coumaphos) pesticides affect the nervous system of human beings. Many Pesticides are not easily digestible, they persist in soil, leach to groundwater and surface water and contaminate the wide environment. DDT and Methyl parathion, BHC like toxic residues are also found in humans and other mammals due to bio-accumulated in food chain causing serious health hazards. This book chapter deals with Role of pesticide application in environmental degradation and its remediation strategies.

KEYWORDS

Bioremediation, Environmental degradation, Pesticides, Toxicants

$\square$ Sudhanshu Bala Nayak, Email: nayaksudhanshubala@gmail.com

(C) 2020 | Agro Environ Media | Agriculture and Environmental Science Academy, Haridwar, India 


\section{Introduction}

Agriculture is the most important sector of the economy in India as it provides food and livelihood security. The industrialization of agriculture has favoured the use of plenty of agrochemicals including fertilizers, pesticides, micronutrients, and plant growth regulators in the agricultural fields (Bruinsma, 2017; Kumar and Kumar, 2019). Pesticides are an integral part of modern agriculture. The use of pesticides in agriculture is obvious for the prevention of crop-damaging pests, fungus, weeds and a number of crop-eating animals like rodents, etc. In India, consumption pattern of pesticides includes insecticides $(61.11 \%)$, herbicides $(22.22 \%)$ and fungicides $(11.11 \%)$. Organophosphates are the most frequently used pesticides followed by neonicotinoid and pyrethroid. One study says that cotton is the high pesticide consuming agriproduct $(93.27 \%)$ followed by vegetables $(87.2 \%)$, wheat $(66.4 \%)$, millet $(52.6 \%)$ and mustard (12.6\%) (Maurya and Malik, 2016; Yadav and Dutta, 2019).

\section{Types of chemical pesticides}

\section{Organophosphate pesticides}

These pesticides affect the nervous system by disrupting the enzyme that regulates acetylcholine, a neurotransmitter. Most organophosphates are insecticides. They were developed during the early 19th century, but their effects on insects, which are similar to their effects on humans, were discovered in 1932. Some of the OP compounds are diazinon, malathion, coumaphos (Ware and Whitacre, 2004; Jat et al., 2016).

\section{Carbamate pesticides}

These pesticides affect the nervous system by disrupting an enzyme that regulates acetylcholine, a neurotransmitter. The enzyme effects are usually reversible. There are several subgroups within the carbamates. Aldicarb, carbofuran, carbaryl, carbosulfan are the example of carbamates.

\section{Organochlorine insecticides}

These were commonly used in the past, but many have been removed from the market due to their health and environmental effects and their persistence effect. DDT, chlordane, aldrin, dieldrin, heptachlor are the common OC compounds.

\section{Pyrethroid pesticides}

These were developed as a synthetic version of the naturally occurring pesticide pyrethrin, which is found in chrysanthemums. They have been modified to increase their stability in the 
environment. Some synthetic pyrethroids are toxic to the nervous system. Deltamethrin, cypermethrin, and permethrin are some of the commonly used pyrethroid (Purdue et al., 2007).

\section{Dynamics of pesticides in the environment}

Many cases of intoxication of farmers, rural workers, and their families did occur during pesticide applications and were documented in reports on poisoning and the effects of synthetic chemicals on human health. It was reported that unintentional poisonings kill an estimated 3, 55,000 people globally each year, and such poisonings are strongly associated with excessive exposure and inappropriate use of toxic chemicals (Briceno et al., 2007; Carvalho, 2017). Dispersion of pesticide residues in the environment and mass killings of nonhuman biotas, such as bees, birds, amphibians, fish, and small mammals, were also reported. Early reports and structured incident reporting systems certainly helped to develop regulations for pesticide applications, including dosage of chemicals and best periods of application. Over the years, a considerable research effort was developed also to understand the behavior of these chemicals in the environment, including their cycling and fate as well as their toxicity to biota (Arias-Estévez et al., 2008; Bourguet and Guillemaud, 2016). The majority of pesticides are not specifically targeting the pest only and during their application. They also affect non-target plants and animals. Repeated application leads to loss of biodiversity (Table 1). Many pesticides are not easily degradable, they persist in soil, leach to groundwater and surface water and contaminate the wide environment. Depending on their chemical properties they can enter the organism, bioaccumulate in food chains and consequently influence also human health (Figure 1).

Table 1. Direct and indirect sources of environmental contamination by pesticides

\begin{tabular}{ll}
\hline Direct sources & Indirect sources \\
\hline Application for pest-control in agriculture & Drift (air), rain, and snow \\
$\begin{array}{l}\text { Application for pest-control in livestock } \\
\text { Soil treatments to control subterranean pests }\end{array}$ & Animal dips \\
$\begin{array}{l}\text { Water treatment to control weeds, mosquitoes, } \\
\text { and others }\end{array}$ & $\begin{array}{l}\text { Sanitation system carrying pesticides from } \\
\text { washing and cleaning of equipment and } \\
\text { containers }\end{array}$ \\
& Dumping of pesticides \\
& $\begin{array}{l}\text { Industrial wastes from pesticides- } \\
\text { manufacturing plants }\end{array}$ \\
& Pesticide spills \\
\hline
\end{tabular}




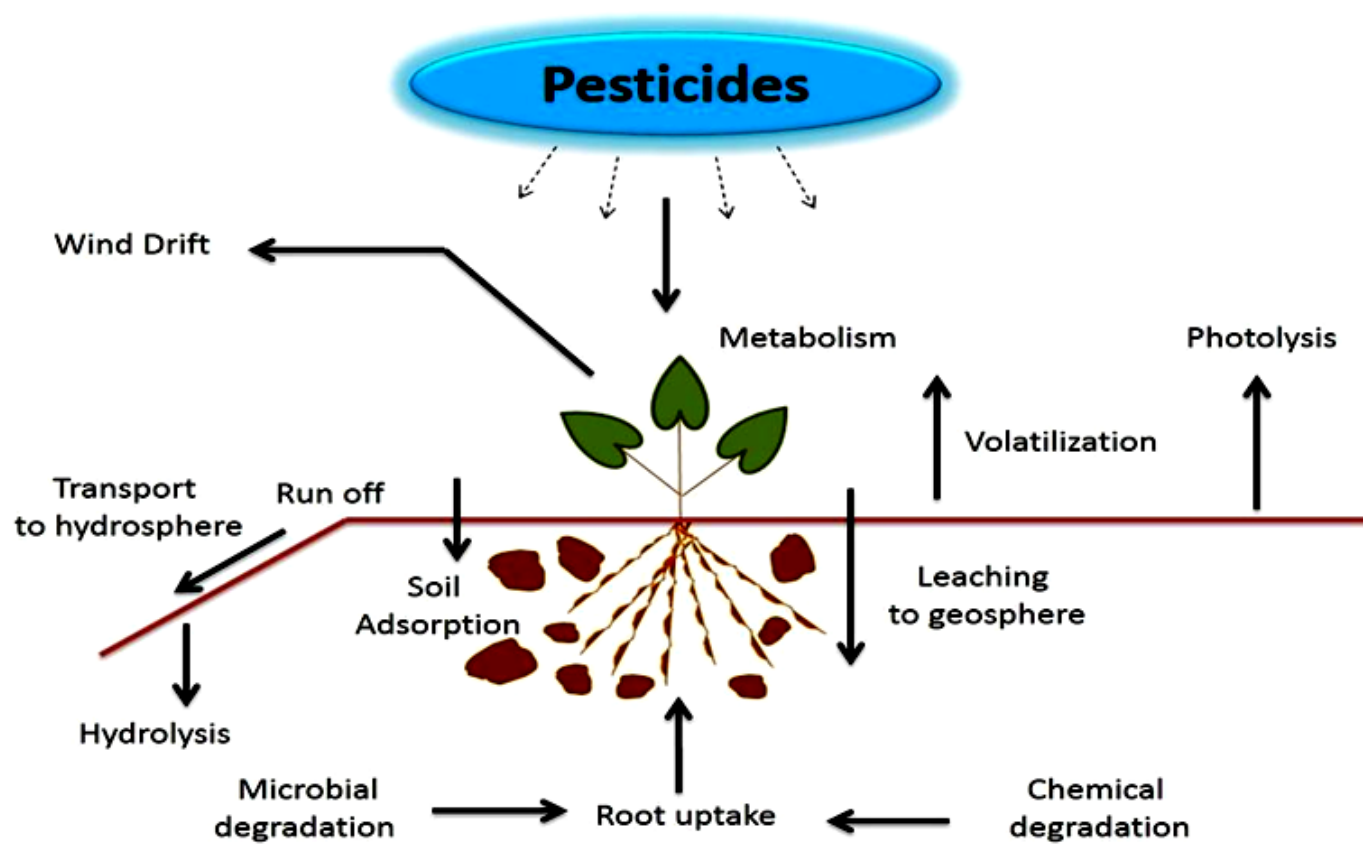

Figure 1. Schematic diagram representing pesticide dispersal in environment.

\section{Environment impacts}

Pesticides present the only group of chemicals that are purposely applied to the environment with the aim to suppress plant and animal pests and to protect agricultural and industrial products. Pesticides can contaminate soil, water, turf, and other vegetation. In addition to killing insects or weeds, pesticides can be toxic to a host of other organisms including birds, fish, and beneficial insects (Kumar et al., 2019). However, the majority of pesticides are not specifically targeting the pest only and during their application, they also affect non-target plants and animals. Repeated application leads to loss of biodiversity. Many pesticides are not easily degradable, they persist in soil, leach to groundwater and surface water and contaminate the wide environment. Depending on their chemical properties, they can enter the organism, bioaccumulate in food chains and consequently influence the environment

\section{Soil contamination}

Pesticides enter the soil via spray drift during foliage treatment, wash-off from treated foliage, release from granulates or from treated seeds in the soil. Some pesticides such as soil fumigants 
and nematicides are applied directly into the soil to control pests and plant diseases presented in soil. The transport, persistence or degradation of pesticides in soil depends on their chemical properties as well as the physical, chemical and biological properties of the soil. All these factors affect sorption/ desorption, volatilization, degradation, uptake by plants, run-off, and leaching of pesticides. Sorption is the most important interaction between soil and pesticides and limits degradation as well as transport in soil. Pesticides bound to soil organic matter or clay particles are less mobile, bioavailable but also less accessible to microbial degradation and thus more persistent. Soil organic matter is the most important factor influencing the sorption and leaching of pesticides in soil. The addition of organic matter to the soil can enhance sorption and reduce the risk of water pollution. The amount and composition of organic matter have a large impact on pesticide sorption. For example, soil rich on humus content is more chemically reactive with pesticides than non-humified soil. Changes in soil $\mathrm{pH}$ or the addition of nitrate fertilizers can induce a release of these residues. There exist also pieces of evidence that some organisms, e.g. plants and earthworms, can uptake and remobilize old tightly bound residues

\section{Water contamination}

Pesticides can get into the water via drift during pesticide spraying, by runoff from the treated area, leaching through the soil. In some cases, pesticides can be applied directly onto the water surface. Water contamination depends mainly on the nature of pesticides (water solubility, hydrophobicity), soil properties, weather conditions, landscape and also on the distance from an application site to a water source. Rapid transport to groundwater may be caused by heavy rainfall shortly after the application of the pesticide to wet soils. Pesticides detected in water bodies are pronofos, dimethoate, chlordane, diuron, prometryn, and fluometuron. Streams and rivers were frequently more polluted than groundwaters and more near the areas with substantial agricultural and/or urban land use.

\section{Impacts on organisms}

Soil organisms: Soil microorganisms are essential for the maintenance of soil structure, transformation, and mineralization of organic matter, making nutrients available for plants. Soil microorganisms are also able to metabolize and degrade a lot of pollutants and pesticides. Microbial degradation can also lead to the formation of more toxic and persistent metabolites. Although soil microbial populations are characterized by fast flexibility and adaptability to changed environmental conditions, the application of pesticides (especially long-term) can cause significant irreversible changes in their population. The inhibition of species, which provide key processes, can have a significant impact on the function of the whole terrestrial ecosystem. Fungicides are found to be toxic to soil fungi and actinomycetes and causing changes in microbial community structure. Other bacterial species, such as nitrification bacteria, are very sensitive to 
pesticides influence. Inhibition of nitrification was proved by sulphonylurea herbicides. Chlorothalonil and dinitrophenyl fungicides such as Mancozeb, Maneb or Zineb have also been shown toxic to nitrification and denitrification bacteria. Organochlorine pesticides suppress symbiotic nitrogen fixation resulting in lower crop yields. DDT and Methyl parathion at levels found in farm soils interfered signaling from the leguminous plants such as alfalfa, peas, and soybeans to symbiotic soil bacteria. This effect, loosely comparable to endocrine disruption effects of pesticides in humans and animals, significantly disrupts $\mathrm{N}_{2}$ fixation. As a consequence, increased dependence on synthetic nitrogenous fertilizer reduced soil fertility and unsustainable long-term crop yields occur. The observations also may explain a trend in the past 40 years toward stagnant crop yields despite record-high use of pesticides and synthetic fertilizers worldwide

Soil invertebrates: Nematodes, springtails, mites and further micro-arthropods, earthworms, spiders, insects, and all these small organisms make up the soil food web and enable decomposition of organic compounds such as leaves; manure, plant residues and they also prey on crop pests. Soil organisms enhance soil aggregation and porosity and thus increasing infiltration and reducing runoff. Earthworms represent the greatest part of the biomass of terrestrial invertebrates (>80 \%) and play an important role in the soil ecosystem. They are used as a bioindicator of soil contamination providing an early warning of the decline in soil quality. They serve as model organisms in toxicity testing. Earthworms are characterized by a high ability to cumulate a lot of pollutants from the soil in their tissues, thus they are used for studying bioaccumulation potential of chemicals. A recent review of pesticide effects on earthworms showed a negative reaction to the growth and reproduction of earthworms by many pesticides. A microcosm study conducted in orchards in South Africa indicated the adverse effects of spraying by pesticides (chlorpyrifos and azinphos methyl) on earthworm's biomass and cholinesterase activity. Earthworms were detrimentally affected by pesticides due to chronic and intermittent exposure. A laboratory experiment that reproduced vineyard conditions in France showed that a mixture of insecticides and/or fungicides at different environmental concentrations caused a neurotoxic effect in earthworms. After a long period of exposure or high concentrations, earthworms were physiologically damaged and could not cope with the high toxicity (Schreck et al., 2008). Chlorpyrifos causes several adverse effects at the cellular level (DNA damage) that indicates physiological stress in the earthworm.

Impact on non-target species: The negative impact of pesticides spraying on invertebrate communities might not be seen instantly but may produce detrimental effects afterward. Decrease in the number of spiders and diversity; and species richness of Collembolan after application of insecticide chlorpyrifos has been reported on grassland pasture in UK (Fountain et al., 2009). Impact of chemical treatment on arthropod community in the agriculture area near Everglades Nation Park, USA. Overall, more arthropod taxa were present in the non-sprayed 
field, with a higher number of predators such as coccinellids than on-field treated by broad-spectrum herbicides and insecticides eleven times during two years. The restriction of herbicides in crop edges has a positive influence on arthropod populations, especially for chick-food insects, Heteroptera, and other herbivores. Predatory insects may be affected indirectly by the exclusion of herbicides alone, or as a result of changes in their prey availability. The effect of pesticides on bees is closely watched because of their crop pollination. However, little is known about the impacts of pesticides on wild pollinators in the field. In a recent study conducted in the Italian agricultural area, monitored species richness of wild bees, bumblebees and butterflies were sampled after pesticide application (Meftaul et al., 2019). They detected the decline of wild bees after repeated application of insecticide fenitrothion. Lower bumblebee and butterfly species richness was found in the more intensively farmed basin with higher pesticide loads. Several articles reported the negative effects of pesticides and intensive agriculture on butterflies' populations and showed positive effects on organic farming. It has been shown that using herbicides to control invasive plants can significantly reduce survival, wing and pupa weight of butterfly at treated areas. The author highlighted the importance of careful consideration in the use of herbicides in habitats harboring at-risk butterfly populations. Reduction of adverse effect may be achieved by applications in late summer and early fall, post-flight season and during larval diapauses (Meftaul et al., 2019).

Amphibians and fishes: Carbaryl has been found toxic for several amphibian species; additional combination with predatory stress causes higher mortality. Herbicide Roundup, glyphosate, caused high mortality of tadpoles and juvenile frogs in an outdoor mesocosms study. Malathion is the most commonly applied insecticide around the world and can be legally directly sprayed over aquatic habitats to control the mosquitoes. A small concentration of malathion caused direct and also an indirect effect on the aquatic food web. Changes in plankton and periphyton abundance and composition consequently affected the growth of frog tadpoles and reduce predation rates on amphibians. Repeated low dose application causes a large impact than a single exposure. All these pieces of evidence might contribute to the explanation of a global decline in amphibian diversity.

Impact on birds: The decline of farmland bird species has been reported over several past decades and often attributed to changes in farming practices, such as increase agrochemical inputs, loss of mixture farming or unfarmed structures. Besides lethal and sublethal effects of pesticides on birds, concern has recently focused on the indirect effects. These effects act mainly via the reduction of food supplies (weeds, invertebrates), especially during breeding or winter seasons. As a consequence insecticide and herbicide applications can lead to the reduction of chick survival and bird population. The time of pesticide application plays also an important role in the availability of food. Several practices (generally Integrated crop management techniques) can 
be used to minimize unwanted effects of pesticides on farmland birds, such as the use of selective pesticides, avoiding spraying during breeding season when crops and weeds are in flower, minimize spray drift or creation of headlands.

\section{Persistence of pesticides}

Approximately 90 percent of pesticides used in agricultural practices never reach their target organisms instead, scattered through the air, soil, and water resulting in detection in air, surface and groundwater, sediment, soil, vegetables and to some extent in foods. To control soil-borne pests and pathogens soil-applied pesticides accumulated residues and metabolites in the soil at unacceptably high levels. (Shalaby and Abdou, 2010). Depending upon the structure of the pesticide and availability of soil factors, pesticide persistence in the soil fluctuates from a week to several years. For instance, chlorinated hydrocarbon insecticides like chlordane persist at least 4-5 years and some times more than 15 years whereas toxic phosphates persist for three months (Niti et al., 2014). The persistence of pesticides poses a threat to livestock and human health.

\section{Pesticide degradation}

Pesticide degradation is the process by which a pesticide is transformed into simpler compounds such as water, carbon dioxide, and ammonia as a result of chemical reactions like hydrolysis, photolysis, and biodegradation (Ortiz-Hernandez et al., 2013). Degradation of pesticides involves both biotic transformation processes-mediated by microorganisms or plants-and abiotic processes such as chemical and photochemical reactions. What transformation processes a given pesticide undergoes is determined by its structural affinity to specific types of transformation, and the environmental conditions it is exposed to as a result of its distribution and transport behavior. For instance, redox gradients in soils, sediments, or aquifers often determine which biotic and/or abiotic transformations can occur. Similarly, photochemical transformations are restricted to compartments exposed to sunlight-e.g., the topmost meter(s) of lakes or rivers, the surfaces of plants, or sub-millimeter layers of soil. The environmental dynamics of pesticides are influenced largely by the various factors operating in the environment and the physicochemical and biological properties of pesticides. The environment consists of the atmosphere (air), hydrosphere (water), lithosphere (soil), and biosphere (biota), each possessing its own physical and chemical and/or biological properties. The biotic and abiotic elements in each component influence the dynamics of pesticides. The environmental dynamics of pesticides are further influenced by the physicochemical properties of pesticides. Properties of pesticides such as hydrophilicity or lipophilicity, partition coefficients, adsorption, vapor pressure, and volatility 
determine the ultimate fate of pesticides in the living and nonliving portions of the systems (Kumar et al., 2013; Vela et al., 2017).

\section{Remediation strategies}

Pesticides convert and degrade them into simpler non-toxic compounds by soil microorganisms' metabolic activities of bacteria, fungi, actinomycetes and plants process called biodegradation. Besides biodegradable pesticides in the soil, there are certain pesticides show complete resistance to biodegradation, called -recalcitrant ( Mulchandani et al., 1999). Different techniques employed for bioremediation depend upon three basic principles i.e. the amenability of the pollutant to biological transformation (biochemistry), the accessibility of the contaminant to microorganisms (Bioavailability) and the opportunity for optimization of biological activity (bioactivity) (Dua et al., 2002). There are two broad ways of bioremediation i.e. in-situ remediation and ex-situ remediation strategies. Bacteria like Alcaligenes, Flavobacterium, Pseudomonas, and Rhodococcus have impressive capabilities of pesticide degradation (Boricha and Fulekar, 2009). Actinomycetes belonging to the genera Arthrobacter, Clavibacter, Noca-rdia, Rhodococcus, Nocardioides and Streptomyces have the potential for the degradation of the pesticides (DeSchrijver and DeMot, 1999). White-rot fungi also have played a significant role in the degradation of pesticides such as lindane, atrazine, diuron, terbuthylazine, metalaxyl, DDT, gamma-hexachlorocyclohexane (g-HCH), dieldrin, aldrin, heptachlor, chlordane, lindane, mirex, etc. (Watanabe et al., 2001). Flammulina velupites, Stereum hirsutum,Coriolus versicolor,Dichomitus squalens, Hypholoma fasciculare, Auricularia auricula, Pleurotus ostreatus species fungi are effective against triazine, phenylurea, dicarboximid, chlorinated organophosphorus compounds. (Uqab et al., 2016). There is another significant inexpensive, environmentally friendly and effective in-situ method called phytoremediation or plant-assisted bioremediation i.e. using plants to clean and restore soil and wastewater for removal of soil contaminants. Plant root systems along with uptake, transformation, volatilization, and rhizodegradation are the important processes used during phytoremediation (Bot and Benites, 2005; Niti et al., 2014). A favorable microenvironment is provided around plant roots to facilitate contaminant degradation (Reichenberger et al., 2007).

\section{Conclusion}

No doubt the current Indian agriculture is loaded with chemicals like pesticides for protecting crops for a larger population food security, the externalities involved in pesticide application created an extra burden on the environment and human societies. The intoxication has spread over many platforms starting from farm families to the tail end consumer in the food chain 
dynamics. The fate of pesticides has serious concern over environmental degradation due to soil, water, air, cropland pollution. The persistence of pesticides has an irreversible long-run negative impact on terrestrial and aquatic species. However, there should have several strategies for safe pesticide production and judicial safe use of pesticides by the farmers. Bioremediation and Phytoremediation can be an effective approach for pesticide degradation. Integrated Pest Management in the integration of other non-chemical practices for sustainable agriculture can be hope for future agriculture in India.

\section{References}

Arias-Estévez, M., Lopez-Periago, E., Martínez-Carballo, E., Simal-Gandara, J., Mejuto, J. C., and Garcia-Río, L. (2008). The mobility and degradation of pesticides in soils and the pollution of groundwater resources. Agriculture, Ecosystems $\mathcal{E}$ Environment, 123(4), 247-260.

Boricha, H. and Fulekar, M.H. (2009). Pseudomonas plecoglossicida as a novel organism for the bioremediation of cypermethrin. Biology and medicine, 1(4): 1-10. https://www.cabdirect.org/cabdirect/abstract/20103234895

Bourguet D. and Guillemaud T. (2016) The hidden and external costs of pesticide use. In: Lichtfouse E. (eds) Sustainable Agriculture Reviews. Sustainable Agriculture Reviews, Vol 19. Springer, Cham, pp. 35-120. https:// doi.org/10.1007/978-3-319-26777-7_2

Bot, A., and Benites, J. (2005). The importance of soil organic matter: Key to drought-resistant soil and sustained food production (No. 80). Food and Agriculture Organization.

Bruinsma, J. (2017). World agriculture: towards 2015/2030: an FAO study. Routledge.

Briceno, G., Palma, G., and Durán, N. (2007). Influence of organic amendment on the biodegradation and movement of pesticides. Critical Reviews in Environmental Science and Technology, 37(3), 233-271.

Carvalho, F.P. (2017). Pesticides, environment, and food safety. Food and Energy Security, 6(2): 48-60.

DeSchrijver A. and DeMot R. (1999). Degradation of pesticides by actinomycetes, Critical Reviews in Microbiology, 25: 85-119.

Dua M., Singh A., Sethunathan N. and Johri A. (2002). Biotechnology and bioremediation: successes and limitations, Applied Microbiology and Biotechnology, 59(2-3): 143-152.

Fountain, M.T., Thomas, R.S., Brown, V.K., Gange, A.C., Murray, P.J. and Symondson, W.O. C. (2009). Effects of nutrient and insecticide treatments on invertebrate numbers and predation on slugs in an upland grassland: A monoclonal antibodybased approach. Agriculture, Ecosystems \& Environment, 131(3-4): 145-153.

Jat, M. K., Kakraliya, G. L., and Kakraliya, S. K. (2016). Insecticides as Environmental Contaminants and Their Remediation. Innovative Farming, 1(4), 134-136.

Kumar, S., Sharma, A.K., Rawat, S.S., Jain, D.K. and Ghosh, S. (2013). Use of pesticides in agriculture and livestock animals and its impact on environment of India. Asian Journal of Environmental Science, 8(1): 51-57.

Kumar, V. and Kumar, P. (2019). Pesticides in agriculture and environment: Impacts on human health. Contaminants in Agriculture and Environment: Health Risks and Remediation, 1, 76.

Kumar, V., Kumar, P. and Singh, J. (2019). An introduction to contaminants in agriculture and environment. Contaminants in Agriculture and Environment: Health Risks and Remediation, 1, 1-8. https://doi.org/10.26832/AESA-2019-CAE-015901

Maurya, P. K., and Malik, D. S. (2016). Bioaccumulation of xenobiotics compound of pesticides in riverine system and its control technique: a critical review. Journal of Industrial Pollution Control, 32(2) 270-278.

Meftaul, I.M., Venkateswarlu, K., Dharmarajan, R., Annamalai, P. and Megharaj, M. (2019). Pesticides in the urban environment: a potential threat that knocks at the door. Science of The Total Environment, 134612. 
Mulchandani A., Kaneva I. and Chen W., (1999). Detoxification of organophosphate pesticides by immobilized Escherichia coli expressing organophosphorus hydrolase on cell surface, Biotechnology and Bioengineering, 63: 216-223.

Niti, C., Sunita, S., Kamlesh, K. and Rakesh, K. (2014). Bioremediation: An emerging technology for remediation of pesticides. Research Journal of Chemistry and Environment, 17(4): 1-10.

Ortiz-Hernández, M.L., Sánchez-Salinas, E., Dantán-González, E. and Castrejón-Godínez, M. L. (2013). Pesticide biodegradation: mechanisms, genetics and strategies to enhance the process. Biodegradation-life of Science, 251-287.

Purdue, M.P., Hoppin, J.A., Blair, A., Dosemeci, M. and Alavanja, M.C. (2007). Occupational exposure to organochlorine insecticides and cancer incidence in the Agricultural Health Study. International Journal of Cancer, 120(3): 642-649.

Reichenberger, S., Bach, M., Skitschak, A., and Frede, H. G. (2007). Mitigation strategies to reduce pesticide inputs into ground -and surface water and their effectiveness; a review. Science of the Total Environment, 384(1-3), 1-35.

Schreck, E., Geret, F., Gontier, L. and Treilhou, M. (2008). Neurotoxic effect and metabolic responses induced by a mixture of six pesticides on the earthworm Aporrectodea caliginosa nocturna. Chemosphere, 71(10): 1832-1839.

Shalaby S.E.M. and Abdou G.Y. (2010). Influence of soil microorganisms and bio- or - organic fertilizers on dissipation of some pesticides in soil and potato tube, Journal of Plant Protection and Research, 50(1): 86-92

Uqab, B., Mudasir, S. and Nazir, R. (2016) Review on Bioremediation of Pesticides. Journal of Bioremediation and Biodegradation, 7: 343.

Vela, N., Pérez-Lucas, G., Fenoll, J., and Navarro, S. (2017). Recent overview on the abatement of pesticide residues in water by photocatalytic treatment using TiO2. Application of Titanium Dioxide, 147.

Ware, G.W. and Whitacre, D.M. (2004). An introduction to insecticides. The Pesticide Book. Willoughby, Ohio: Meister Pub

Watanabe, K., Kodama, Y., Syutsubo, K. and Harayama, S. (2001). Molecular characterization of bacterial populations in petroleum-contaminated groundwater discharged from underground crude oil storage cavities. Applied Environmental Microbiology, 66(11): 4803-4809.

Yadav, S. and Dutta, S. (2019). A Study of Pesticide Consumption Pattern and Farmer's Perceptions towards Pesticides: A Case of Tijara Tehsil, Alwar (Rajasthan). International Journal of Current Microbiology and Applied Sciences, 8(4): 96-104.

Cite this chapter as: Nayak, S.B., Sahoo, A.K., K., E. and Rao K.S. (2020). Role of pesticide application in environmental degradation and its remediation strategies. In: Environmental Degradation: Causes and Remediation Strategies, Volume 1, Eds. Kumar, V., Singh, J. and Kumar, P., pp. 36-46, https://doi.org/10.26832/aesa-2020-edcrs-03 